\title{
Sensitization to Aspergillus species is associated with frequent exacerbations in severe asthma
}

This article was published in the following Dove Press journal:

Journal of Asthma and Allergy

21 April 2017

Number of times this article has been viewed

\section{Ken Junyang Goh' \\ Anthony Chau Ang Yii ${ }^{1,2}$ \\ Therese Sophie Lapperre ${ }^{1,2}$ \\ Adrian KW Chan ${ }^{1-3}$ \\ Fook Tim Chew ${ }^{4}$ \\ Sanjay H Chotirmall ${ }^{5, *}$ \\ Mariko Siyue Koh ${ }^{1-3, *}$ \\ 'Department of Respiratory and Critical Care Medicine, Singapore General Hospital, ${ }^{2}$ Duke-National University of Singapore Medical \\ School, ${ }^{3}$ Allergy Centre, Singapore General Hospital, ${ }^{4}$ Department of Biological Sciences, Faculty of Science, National University of Singapore, ${ }^{5}$ Lee Kong Chian School of Medicine, Nanyang Technological University, Singapore}

*These authors contributed equally to this work
Correspondence: Sanjay H Chotirmall Lee Kong Chian School of Medicine, Level 12 Clinical Sciences Building (CSB), I I Mandalay Road, 308232 Singapore Email schotirmall@ntu.edu.sg
Background: Severe asthma is a largely heterogeneous disease with varying phenotypic profiles. The relationship between specific allergen sensitization and asthma severity, particularly in Asia, remains unclear. We aim to study the prevalence of specific allergen sensitization patterns and investigate their association with outcomes in a severe asthma cohort in an Asian setting. Methods: We conducted a cross-sectional study of patients receiving step 4 or 5 Global Initiative for Asthma treatment. Univariate and multivariate analyses were performed to assess the association between sensitization to a specific identifiable allergen by skin prick test (SPT) and uncontrolled asthma (defined in our study as the use of $\geq 2$ steroid bursts or hospitalization in the past year, a history of near-fatal asthma or evidence of airflow obstruction on spirometry). Results: Two hundred and six severe asthma patients (mean age $45 \pm 17$ years, 99 [48.1\%] male) were evaluated. Of them, $78.2 \%$ had a positive SPT to one or more allergens. The most common allergen to which patients were sensitized was house dust mites (Blomia tropicalis, Dermatophagoides pteronyssinus and Dermatophagoides farinae). Also, 11.7\% were sensitized to Aspergillus species. On multivariate analysis, Aspergillus sensitization was associated with uncontrolled asthma (odds ratio 6.07, 95\% confidence interval 1.80-20.51). In particular, Aspergillus sensitization was independently associated with the use of $\geq 2$ steroid bursts in the past year (odds ratio 3.05, 95\% confidence interval 1.04-8.95). No similar associations of uncontrolled asthma with sensitization to any other allergens were found.

Conclusion: High allergen, specifically Aspergillus sensitization was observed in the Asian population with severe asthma by SPT. Aspergillus sensitization was specifically associated with frequent exacerbations and a greater corticosteroid requirement. An improved understanding of the severe asthma with Aspergillus sensitization phenotype is warranted, which is likely a subgroup of severe asthma with fungal sensitization.

Keywords: atopy, airway, fungus, Aspergillus, outcomes, prognosis

\section{Introduction}

Asthma is a heterogeneous disease with different clinical phenotypes. ${ }^{1,2}$ Each phenotype can demonstrate one or more molecular endotypes amenable to therapeutic intervention. While allergic asthma remains a common asthma phenotype, many conflicting results persist, specifically on the role of allergen sensitization in determining the severity and prognosis of severe asthma. ${ }^{3}$ Among the various allergens, fungal sensitization is associated with increased asthma severity, ${ }^{4-6}$ evidenced by increased hospital admissions for exacerbations and poorer lung function. ${ }^{7,8}$ The entity of severe asthma with fungal sensitization (SAFS) has, therefore, been coined, which is characterized by the presence of severe asthma, fungal sensitization and the exclusion of allergic 
bronchopulmonary aspergillosis (ABPA). ${ }^{9}$ This proposed subtype of severe asthma is clinically recognized; however, data to support its true prevalence and treatment outcomes remain unclear.

Studies focused on fungal sensitization in asthmatics are heterogeneous and have, to date, included differing asthma severities, making their conclusions difficult to interpret, particularly in the context of severe asthma. Data remain lacking in patients with severe asthma, who, we hypothesize, would likely be most affected by documented fungal sensitization. Importantly, current literature is focused largely on the Caucasian population, with a consequent paucity of literature on allergen sensitization in the severe asthma population in Asia. This is critical because allergen sensitization in the east is likely to be different from other parts of the world due to complex interplay between genetics and environmental ethnogeography in determining an individual's sensitization state. We, therefore, studied the prevalence of sensitization including Aspergillus species and its association with asthma-related outcomes in a multiethnic South East Asian population with severe asthma.

\section{Methods}

This was a cross-sectional study conducted at Singapore General Hospital. All recruited patients were at minimum receiving step 4 or 5 Global Initiative for Asthma (GINA) treatment, that is, they required a combination of medium to high-dose inhaled corticosteroids ( $>250 \mu \mathrm{g}$ equivalent of fluticasone) and long-acting beta agonists. Diagnosis of asthma was made on the basis of a history of episodic wheeze and dyspnea, clinical examination and supported by spirometry (reversibility of forced expiratory volume in 1 second $\left[\mathrm{FEV}_{1}\right]$ of $>12 \%$ and $200 \mathrm{~mL}$, or demonstration of bronchial hyperresponsiveness with a positive methacholine challenge test or $\mathrm{FEV}_{1}$ variability of $>15 \%$ ). Demographic characteristics including age, ethnicity, gender, age of asthma onset, presence of allergic rhinitis, family history of asthma, smoking status and body mass index (BMI) were collated. Skin prick tests (SPTs) were performed with a comprehensive panel (Stallergenes, Antony, Hauts-de-Seine, France) that included the following extracts: house dust mites (HDM; Blomia tropicalis [BT], Dermatophagoides pteronyssinus [DP] and Dermatophagoides farinae [DF]), dog and cat dander, mixed feathers, cockroach and Aspergillus mix (Aspergillus fumigatus, Aspergillus nidulans, Aspergillus niger). The negative control was glycerin and the positive control histamine, both at $10 \mathrm{mg} /$ $\mathrm{mL}$. A positive response was defined as any allergen-induced wheal of $3 \mathrm{~mm}$ greater than the negative control, 15 minutes after application. Asthma control test scores were recorded at baseline. Spirometry was performed as per the American Thoracic Society/European Respiratory Society guidelines, using a Medgraphics (St Paul, MN, USA) spirometer. Indicators of uncontrolled asthma (defined as $\geq 2$ steroid bursts required for asthma exacerbations in the past year, $\geq 1$ asthma exacerbation requiring hospitalization in the past year, a history of near-fatal asthma, i.e., received mechanical ventilation for severe asthma exacerbation, or $\mathrm{FEV}_{1}<80 \%$ predicted and $\mathrm{FEV}_{1} /$ forced vital capacity $[\mathrm{FVC}]<0.7$ on pulmonary function testing) were determined by history and correlated with electronic health records and clinical investigations. Ethics approval from the Singhealth Institutional Review Board was obtained (CIRB: 2010/810/C) including written consent from the participants.

\section{Statistical analysis}

Continuous variables are presented as mean \pm standard deviation (SD) or median (interquartile range [IQR]), and comparisons between groups were performed using independent $t$-tests and the Mann-Whitney $U$ test, respectively, for normal and non-normal data sets. Categorical variables are presented as numbers (percentages), and comparisons were performed using the Pearson's $\chi^{2}$ or the Fisher's exact test, where appropriate. Comparisons between three variables were performed using one-way analysis of variance and Kruskal-Wallis tests for normal and non-normal data sets, respectively. Multivariate logistical regression was performed to estimate adjusted odds ratios (ORs) for the associations between specific allergen sensitization and indicators of uncontrolled asthma, taking into account potential confounding factors (age, ethnicity, gender, BMI, smoking history and all other allergens). All data were assessed using Statistical Package for the Social Sciences (version 17.0; SPSS Inc., Chicago, IL, USA) for analysis, and $p$ values $<0.05$ were considered statistically significant.

\section{Results}

\section{Patient characteristics}

Two hundred and six patients were included and their baseline characteristics are presented in Table 1. The cohort consisted of a broad ethnic distribution including $61.2 \%$ Chinese, $16.5 \%$ Malay, $14.1 \%$ Indian and $8.3 \%$ other ethnic groups. Patients were on treatment with a median of three (IQR: 2-3) controllers (controllers defined as inhaled corticosteroids, long-acting beta agonists, theophylline, leukotriene receptor antagonists, long-term systemic steroids, omalizumab or long-acting anticholinergics). All patients were on two or more controllers, with $91(44.2 \%)$ patients on three 
controllers and $24(11.6 \%)$ on four or more controllers. The median asthma control test score recorded at baseline was 18 (IQR: $15-21)$. Forty-five (21.8\%) patients required $\geq 2$

Table I Characteristics of patients with severe asthma $(\mathrm{N}=206)$

\begin{tabular}{|c|c|}
\hline \multicolumn{2}{|l|}{ Demographics } \\
\hline Age (years) & $48 \pm 17$ \\
\hline Gender (male) & $99(48.1)$ \\
\hline \multicolumn{2}{|l|}{ Ethnicity } \\
\hline Chinese & $126(61.2)$ \\
\hline Malay & $34(16.5)$ \\
\hline Indian & $29(14.1)$ \\
\hline Others & $17(8.3)$ \\
\hline Body mass index $\left(\mathrm{kg} / \mathrm{m}^{2}\right)$ & $26.0 \pm 6.6$ \\
\hline Asthma control test score & $18(|5-2|)$ \\
\hline Age of onset (years) & $22(10-40)$ \\
\hline Family history of asthma & $50(24.3)$ \\
\hline Allergic rhinitis & $130(63.1)$ \\
\hline \multicolumn{2}{|l|}{ Number of controllers } \\
\hline Two & $91(44.2)$ \\
\hline Three & $91(44.2)$ \\
\hline$\geq$ Four & $24(11.6)$ \\
\hline \multicolumn{2}{|l|}{ Pulmonary function test } \\
\hline $\mathrm{FEV}_{1}, \%$ of predicted & $7 I \pm 20$ \\
\hline FVC, \% of predicted & $76 \pm 17$ \\
\hline $\mathrm{FEV}_{1} / \mathrm{FVC}$ & $0.73 \pm 0.13$ \\
\hline \multicolumn{2}{|l|}{ Indicators of uncontrolled asthma } \\
\hline$\geq 2$ steroid bursts in the past year & $45(21.8)$ \\
\hline Hospitalization in the past year & $35(17.0)$ \\
\hline History of near-fatal asthma & II (6.3) \\
\hline $\mathrm{FEV}_{1}<80 \%$ predicted and $\mathrm{FEV}_{1} / \mathrm{FVC}<0.7$ & $69(33.5)$ \\
\hline Any of the above & $109(52.9)$ \\
\hline
\end{tabular}

Notes: Values are expressed as mean \pm standard deviation, median (interquartile range) and numbers (percentage). Controllers include inhaled corticosteroids, long-acting beta agonists, theophylline, leukotriene receptor antagonists, long-term steroids, omalizumab or anticholinergics.

Abbreviations: $\mathrm{FEV}_{1}$, forced expiratory volume in I second; FVC, forced vital capacity. steroid bursts for asthma exacerbations in the past year, 35 (17.0\%) patients had at least one hospitalization for asthma exacerbation in the past year, $11(6.3 \%)$ patients had a history of near-fatal asthma and 69 (33.5\%) patients had FEV $<80 \%$ predicted and $\mathrm{FEV}_{1} / \mathrm{FVC}<0.7$ on pulmonary function testing. Overall, $109(53.9 \%)$ patients had one or more of the abovementioned indicators of uncontrolled asthma.

\section{Prevalence of allergen sensitization}

One hundred and sixty-two (78.6\%) patients had a positive SPT to one or more allergen extracts (Figure 1). HDM sensitization was the most common: $70.4 \%, 70.9 \%$ and $69.4 \%$ of patients were sensitized to BT, DP and DF, respectively. The other sensitization profiles are: dog dander $(32.0 \%)$, cat dander (33.0\%), cockroach (23.3\%), mixed feathers (11.2\%) and Aspergillus mix (11.7\%). Overall, patients were sensitized to a median of three allergens (IQR: 1-5), and 96 (46.6\%) patients had sensitization to four or more allergens. Twelve patients in our study had requested for the removal of dog dander extract testing during SPT due to religious preference. These were taken to have a negative response on the SPT for dog dander for the purpose of analysis.

\section{Determinants of uncontrolled asthma in a cohort of severe asthma}

We compared the baseline characteristics and allergen sensitization profiles of severe asthma patients with and without indicators of uncontrolled asthma (Table 2). Patients with uncontrolled asthma had a higher rate of sensitization to Aspergillus (18.3\% in uncontrolled asthma and $4.1 \%$ in

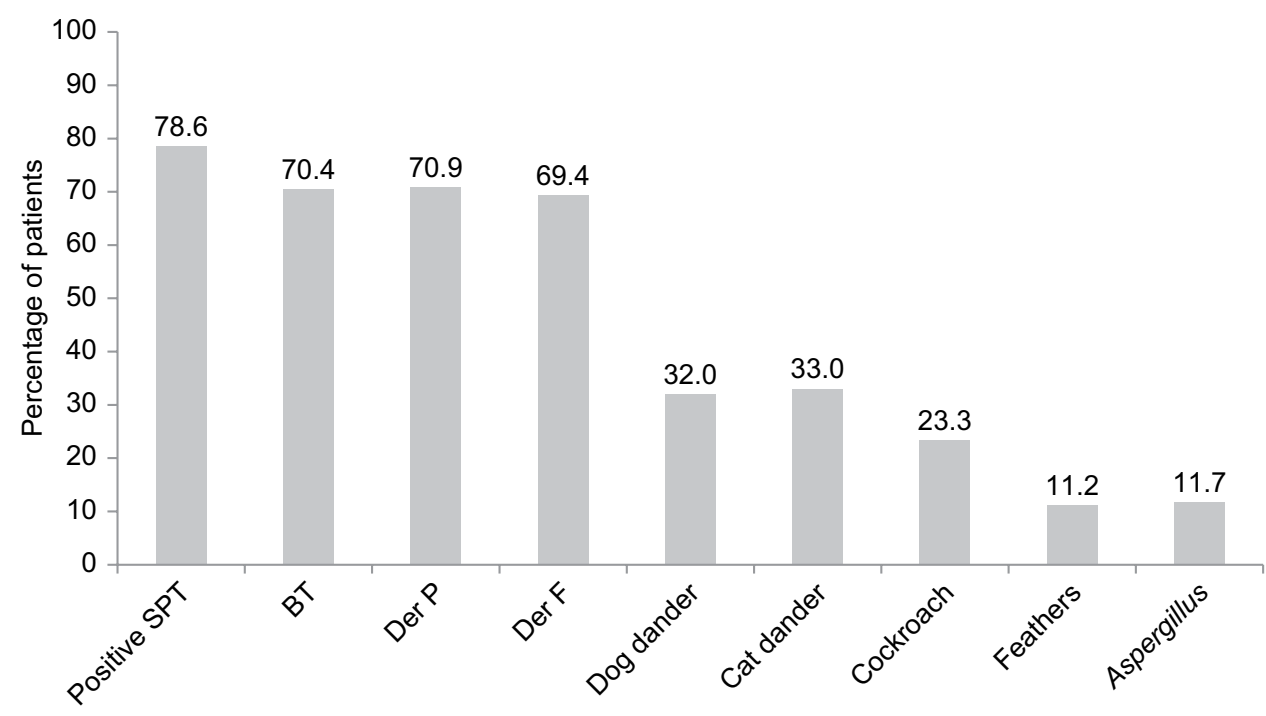

Figure I Prevalence of allergen sensitization in patients with severe asthma in an Asian cohort $(\mathrm{N}=206)$.

Abbreviations: BT, Blomia tropicalis; Der F, Dermatophagoides farinae; Der P, Dermatophagoides pteronyssinus; SPT, skin prick test. 
Table 2 Characteristics of patients with controlled and uncontrolled asthma, defined by one or more of the following: $\geq 2$ steroid bursts in the past year, hospitalization in the past year, a history of near-fatal asthma or FEV $<80 \%$ predicted with FEV,/FVC $<0.7$

\begin{tabular}{|c|c|c|c|}
\hline Patient characteristics & $\begin{array}{l}\text { Controlled } \\
\text { asthma }(n=97)\end{array}$ & $\begin{array}{l}\text { Uncontrolled } \\
\text { asthma }(n=109)\end{array}$ & p-value \\
\hline \multicolumn{4}{|l|}{ Demographics } \\
\hline Age (years) & $44 \pm 17$ & $52 \pm 18$ & $<0.001$ \\
\hline Gender (male) & $51(52.6)$ & $48(44.0)$ & NS \\
\hline Ethnicity & & & NS \\
\hline Chinese & $56(57.7)$ & $70(64.2)$ & \\
\hline Malay & $19(19.6)$ & 15 (13.8) & \\
\hline Indian & $13(13.4)$ & $16(14.7)$ & \\
\hline Others & $9(9.3)$ & $8(7.3)$ & \\
\hline Body mass index $\left(\mathrm{kg} / \mathrm{m}^{2}\right)$ & $26.5 \pm 6.7$ & $25.6 \pm 6.5$ & NS \\
\hline Asthma control test score & $17(14-20)$ & $19(15-22)$ & NS \\
\hline Age of onset (years) & $18(6-37)$ & $25(10-44)$ & NS \\
\hline Active or ex-smoker & $17(17.5)$ & $24(22.0)$ & NS \\
\hline Eosinophil count (109/L) & $0.41(0.26-0.64)^{*}$ & $0.64(0.29-1.24)^{*}$ & 0.006 \\
\hline $\mathrm{FEV}_{1}(\%$ predicted $)$ & $79.7 \pm 17.7$ & $64.5 \pm 19.9$ & $<0.001$ \\
\hline $\mathrm{FEV}_{1} / \mathrm{FVC}$ & $81.2 \pm 7.3$ & $65.8 \pm 13.3$ & $<0.001$ \\
\hline \multicolumn{4}{|l|}{ Allergen sensitization } \\
\hline Positive skin prick test & $74(76.3)$ & $88(80.7)$ & NS \\
\hline Blomia tropicalis & $68(70.1)$ & $77(70.6)$ & NS \\
\hline Dermatophagoides pteronyssinus & $70(72.2)$ & $76(69.7)$ & NS \\
\hline Dermatophagoides farinae & $67(69.1)$ & $76(69.7)$ & NS \\
\hline Dog dander & $33(34.0)$ & $33(30.3)$ & NS \\
\hline Cat dander & $31(32.0)$ & $37(33.9)$ & NS \\
\hline Feather & $9(9.3)$ & $14(12.8)$ & NS \\
\hline Cockroach & $22(22.7)$ & $26(23.9)$ & NS \\
\hline Aspergillus & $4(4.1)$ & $20(18.3)$ & 0.001 \\
\hline Sensitization to $\geq 4$ allergens & $42(43.3)$ & $54(49.5)$ & NS \\
\hline Number of sensitized allergens & $3(I-5)$ & $3(2-5)$ & NS \\
\hline
\end{tabular}

Notes: Values are expressed as mean \pm standard deviation, median (interquartile range), and numbers (percentage). *Eosinophil counts available for 69 and 80 patients with controlled asthma and uncontrolled asthma, respectively.

Abbreviations: $\mathrm{FEV}_{1}$, forced expiratory volume in I second; FVC, forced vital capacity; NS, not significant.

controlled asthma, $p=0.001$ ). There were no significant differences found in the sensitization patterns to other allergens. In addition, no differences were found with regard to the number of allergens to which an individual patient was sensitized.

Patients with uncontrolled asthma were older $(52 \pm 18$ years in uncontrolled asthma and $44 \pm 17$ years in controlled asthma, $p<0.001)$ and had higher serum eosinophil counts (0.64 [IQR: $0.29-1.24] \times 10^{9} / \mathrm{L}$ in uncontrolled asthma and 0.41 [IQR: $0.26-0.64] \times 10^{9} / \mathrm{L}$ in controlled asthma, $p=0.006$ ). Patients with uncontrolled asthma had lower percentage (\%) predicted $\mathrm{FEV}_{1}(64.5 \pm 19.9$ vs $79.7 \pm 17.7, p<0.001)$ and $\mathrm{FEV}_{1} /$ $\mathrm{FVC}$ ratios $(65.8 \pm 13.3$ vs $81.2 \pm 7.3, p<0.001)$. There were no significant differences in gender, ethnicity, BMI or smoking history based on asthma control status.

\section{Effect of Aspergillus and other allergens sensitization status on clinical severe asthma outcomes}

Patients sensitized to Aspergillus were found to have higher steroid requirements (use of $\geq 2$ steroid bursts in the past year): $37.5 \%$ in sensitized vs $19.8 \%$ in nonsensitized, $p=0.048$ (Table 3). A higher proportion of patients with Aspergillus sensitization had evidence of airflow obstruction (defined as $\mathrm{FEV}_{1}<80 \%$ predicted and $\left.\mathrm{FEV}_{1} / \mathrm{FVC}<0.7\right): 54.2 \%$ vs $30.8 \%, p=0.022$ (Table 3 ). Twenty (83.3\%) patients with Aspergillus sensitization had one or more indicators of uncontrolled asthma, as compared to $89(48.9 \%)$ patients without Aspergillus sensitization ( $p=0.001$ ).

We next analyzed the impact of allergen sensitization on asthma control with adjustment for potential confounding patient characteristics of age, gender, ethnicity, BMI and smoking history as well as the presence or absence of sensitization to specific allergens (Figure 2). Aspergillus sensitization was found to be independently associated with uncontrolled asthma (OR 6.07, 95\% confidence interval [CI]: 1.80-20.51). In particular, Aspergillus sensitization was independently associated with the use of $\geq 2$ steroid bursts in the past year (OR 3.05, 95\% CI: 1.04-8.95; Table 4). Similar results were obtained following the addition of eosinophil counts to the multivariate analysis: Aspergillus sensitization was associated 
Table 3 Characteristics of patients with and without sensitization to Aspergillus

\begin{tabular}{|c|c|c|c|}
\hline Patient characteristics and outcomes & No sensitization to Aspergillus $(\mathrm{n}=182)$ & Sensitization to Aspergillus $(\mathrm{n}=\mathbf{2 4})$ & $p$-value \\
\hline \multicolumn{4}{|l|}{ Demographics } \\
\hline Age (years) & $48 \pm 18$ & $51 \pm 18$ & NS \\
\hline Gender (male) & $83(45.6)$ & $16(66.7)$ & 0.052 \\
\hline Ethnicity & & & NS \\
\hline Chinese & $107(58.8)$ & $19(79.2)$ & \\
\hline Malay & $32(17.6)$ & $2(8.3)$ & \\
\hline Indian & $28(15.4)$ & $\mathrm{I}(4.2)$ & \\
\hline Others & $15(8.2)$ & $2(8.3)$ & \\
\hline Body mass index $\left(\mathrm{kg} / \mathrm{m}^{2}\right)$ & $26.1 \pm 6.7$ & $25.4 \pm 5.7$ & NS \\
\hline Asthma control test score & $18(|5-2|)$ & $20(15-23)$ & NS \\
\hline Active or ex-smoker & $35(19.2)$ & $6(25.0)$ & NS \\
\hline Age of onset (years) & $21(8-39)$ & $24(10-49)$ & NS \\
\hline Eosinophil count $\left(\times 10^{9} / \mathrm{L}\right)$ & $0.50(0.28-0.74)^{*}$ & $0.58(0.25-0.95)^{*}$ & 0.006 \\
\hline $\mathrm{FEV}_{1}(\%$ predicted) & $72.3 \pm 19.6$ & $67.0 \pm 25.2$ & NS \\
\hline $\mathrm{FEV}_{1} / \mathrm{FVC}$ & $74.2 \pm 12.6$ & $64.2 \pm 15.3$ & 0.005 \\
\hline \multicolumn{4}{|l|}{ Indicators of uncontrolled asthma } \\
\hline$\geq 2$ Steroid bursts in the past year & $36(19.8)$ & $9(37.5)$ & 0.048 \\
\hline Hospitalization in the past year & $30(16.5)$ & $5(20.8)$ & NS \\
\hline History of near-fatal asthma & $10(5.5)$ & $3(12.5)$ & NS \\
\hline $\mathrm{FEV}_{1}<80 \%$ predicted and $\mathrm{FEV} / \mathrm{FVC}<0.7$ & $56(30.8)$ & $13(54.2)$ & 0.022 \\
\hline Any of the above & $89(48.9)$ & $20(83.3)$ & 0.001 \\
\hline
\end{tabular}

Notes: Values are expressed as mean \pm standard deviation, median (interquartile range) and numbers (percentage). *Eosinophil counts available for 130 and 19 patients with no sensitization to Aspergillus and with sensitization to Aspergillus, respectively.

Abbreviations: FEV , forced expiratory volume in I second; FVC, forced vital capacity; NS, not significant.

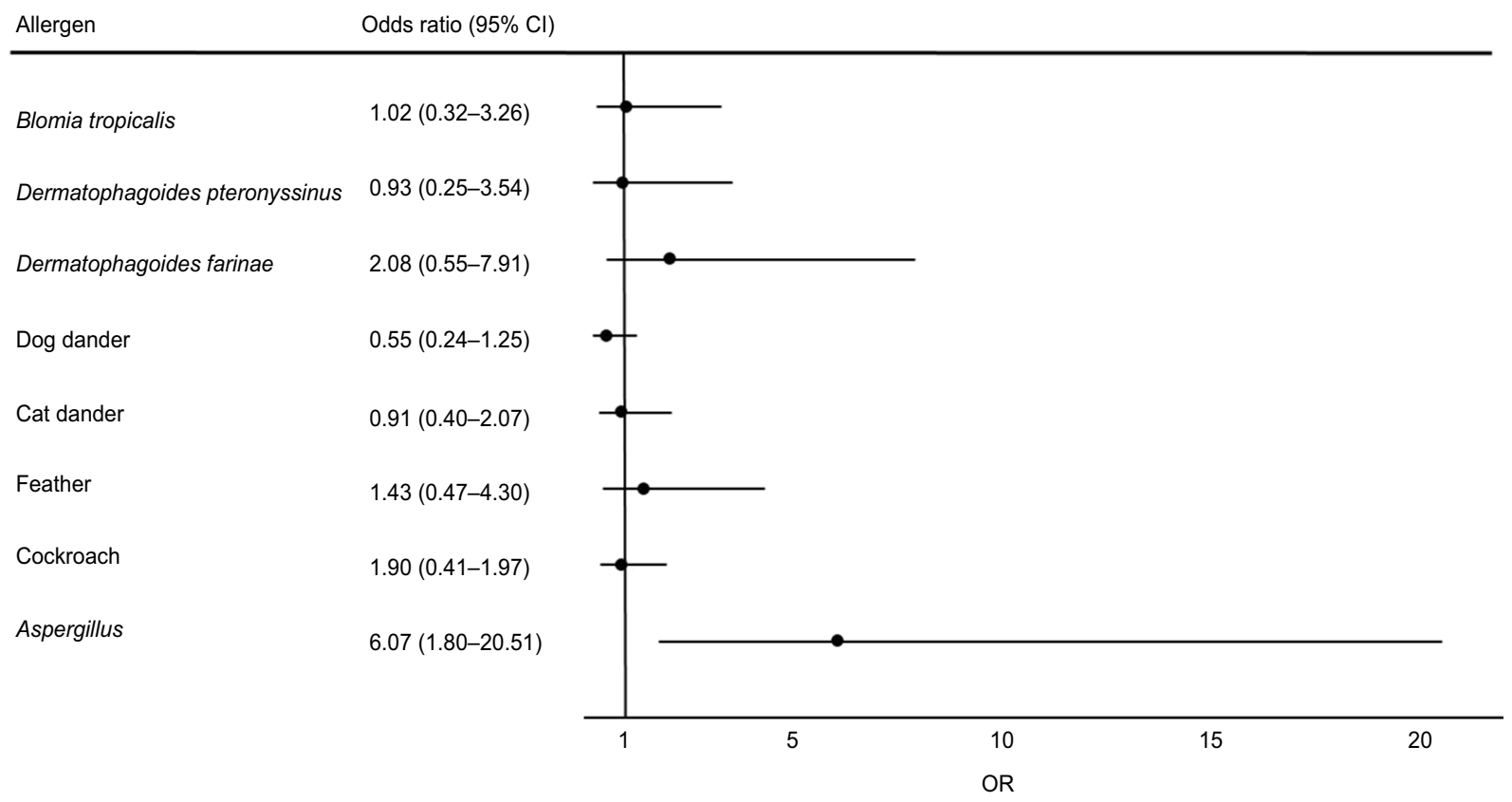

Figure 2 Multivariate analyses of allergen sensitization associated with indicators of uncontrolled asthma.

Note: Age, gender, ethnicity, body mass index, smoking history (active or ex-smoker) and all other allergens were included in the multivariate analyses.

Abbreviations: $\mathrm{Cl}$, confidence intervals; $\mathrm{OR}$, odds ratio.

with uncontrolled asthma (OR 23.0, 95\% CI: 2.70-195.35) and the use of $\geq 2$ steroid bursts in the past year (OR 3.97, 95\% CI: 1.17-13.52). No significant associations were found with the presence of sensitization to any other allergens (Figure 2).

\section{Baseline characteristics and outcomes of patients based on ethnicity}

Baseline characteristics and outcomes of patients based on ethnicity are presented in Table 5. The other 17 patients 
Table 4 Multivariate analyses of Aspergillus sensitization associated with indicators of uncontrolled asthma

\begin{tabular}{|c|c|c|}
\hline Indicators of uncontrolled asthma & Adjusted ORs & p-value \\
\hline$\geq 2$ Steroid bursts in the past year, hospitalization in the past year, history & $6.07(\mathrm{I} .80-20.5 \mathrm{I})$ & 0.004 \\
\hline \multicolumn{3}{|l|}{ of near-fatal asthma or $\mathrm{FEV},<80 \%$ predicted with $\mathrm{FEV}_{1} / \mathrm{FVC}<0.7$} \\
\hline ACT $<20$ & $0.74(0.26-2.14)$ & NS \\
\hline$\geq 2$ Steroid bursts in the past year & $3.05(1.04-8.95)$ & 0.042 \\
\hline Hospitalization in the past year & $2.47(0.70-8.70)$ & NS \\
\hline History of near-fatal asthma & $3.28(0.62-17.36)$ & NS \\
\hline $\mathrm{FEV}_{1}<80 \%$ predicted with $\mathrm{FEV} / \mathrm{FVC}<0.7$ & $2.59(0.90-7.4 \mathrm{I})$ & 0.077 \\
\hline
\end{tabular}

Note: Age, gender, ethnicity, body mass index, smoking history (active or ex-smoker) and all other allergens were included in the multivariate analyses. Abbreviations: $\mathrm{ACT}$, asthma control test; $\mathrm{FEV}_{1}$, forced expiratory volume in I second; FVC, forced vital capacity; NS, not significant; OR, odds ratio.

Table 5 Characteristics of patients with severe asthma based on ethnicity

\begin{tabular}{|c|c|c|c|c|}
\hline Patient characteristics and outcomes & Chinese $(n=126)$ & Malay $(n=34)$ & Indian $(n=29)$ & $p$-value \\
\hline \multicolumn{5}{|l|}{ Demographics } \\
\hline Age (years) & $50 \pm 19$ & $42 \pm 13$ & $46 \pm 17$ & NS \\
\hline Gender (male) & $69(54.8)$ & $9(26.5)$ & II (37.9) & 0.008 \\
\hline Body mass index $\left(\mathrm{kg} / \mathrm{m}^{2}\right)$ & $24.1 \pm 4.3$ & $30.0 \pm 10.0$ & $29.0 \pm 7.9$ & $<0.001$ \\
\hline Age of onset (years) & $26(10-45)$ & $19(5-39)$ & $20(8-37)$ & NS \\
\hline Active or ex-smoker & $27(21.4)$ & $8(23.5)$ & $3(10.1)$ & NS \\
\hline Eosinophil count $\left(10^{9} / \mathrm{L}\right)$ & $0.62 \pm 0.63 *$ & $0.80 \pm 0.62 *$ & $1.02 \pm 1.16 *$ & NS \\
\hline $\mathrm{FEV}_{1}(\%$ predicted $)$ & $73 \pm 22$ & $71 \pm 19$ & $68 \pm 13$ & NS \\
\hline $\mathrm{FEV}_{1} / \mathrm{FVC}$ & $71 \pm 14$ & $76 \pm 13$ & $79 \pm 7$ & 0.006 \\
\hline \multicolumn{5}{|l|}{ Allergen sensitization } \\
\hline Positive skin prick test & $101(80.2)$ & $25(73.5)$ & $21(72.4)$ & NS \\
\hline Blomia tropicalis & $93(73.8)$ & $21(61.8)$ & $18(62.1)$ & NS \\
\hline Dermatophagoides pteronyssinus & $90(71.4)$ & $23(67.6)$ & $20(69.0)$ & NS \\
\hline Dermatophagoides farinae & $92(73.0)$ & $22(64.7)$ & $15(5 \mid .7)$ & NS \\
\hline Dog dander & $4 \mathrm{I}(32.5)$ & $9(26.5)$ & $20(69.0)$ & NS \\
\hline Cat dander & $43(34.1)$ & $9(26.5)$ & $8(26.6)$ & NS \\
\hline Feather & II (8.7) & $5(14.7)$ & $7(24.1)$ & NS \\
\hline Cockroach & $31(24.6)$ & $9(26.5)$ & $2(6.9)$ & NS \\
\hline Aspergillus & $19(15.1)$ & $2(5.9)$ & I (3.4) & NS \\
\hline Sensitization to $\geq 4$ allergens & $64(50.8)$ & $15(44.1)$ & $8(27.6)$ & NS \\
\hline Number of sensitized allergens & 101 (80.2) & $25(73.5)$ & $21(72.4)$ & NS \\
\hline \multicolumn{5}{|l|}{ Indicators of uncontrolled asthma } \\
\hline$\geq 2$ Steroid bursts in the past year & $28(22.2)$ & $7(20.6)$ & $9(31.0)$ & NS \\
\hline Hospitalization in the past year & $18(14.3)$ & $10(29.4)$ & $6(20.7)$ & NS \\
\hline History of near-fatal asthma & $9(7.1)$ & I (2.9) & $2(6.9)$ & NS \\
\hline $\mathrm{FEV}_{1}<80 \%$ predicted and $\mathrm{FEV}_{1} / \mathrm{FVC}<0.7$ & $48(38.1)$ & $9(26.5)$ & $5(17.2)$ & NS \\
\hline Any of the above & $70(55.6)$ & $15(44.1)$ & $16(55.2)$ & NS \\
\hline
\end{tabular}

Notes: Values are expressed as mean \pm standard deviation, median (interquartile range), and numbers (percentage). *Eosinophil counts available for 92,24 and 22 patients of Chinese, Malay and Indian ethnicity, respectively.

Abbreviations: $\mathrm{FEV}_{1}$, forced expiratory volume in I second; FVC, forced vital capacity; NS, not significant.

were from various other ethnicities: nine Eurasians, one Caucasian, with the rest (seven patients) consisting of Pakistanis, Bangladeshis and Sri Lankans. Chinese patients had a higher proportion of males $(54.8 \%$ vs $26.5 \%, p=0.003)$ and had a lower BMI $\left(\mathrm{kg} / \mathrm{m}^{2}\right)$, compared to Malay $(24.1 \pm 4.3$ vs $30.0 \pm 10.0, p<0.001)$ or Indian $(24.1 \pm 4.3$ vs $29.0 \pm 7.9$, $p<0.001)$ patients. Chinese patients also had lower FEV1/ FVC ratios compared to Indian patients ( $71 \pm 14$ vs $79 \pm 7$, $p<0.001)$. Sensitization to allergens, however, did not differ among the ethnic groups. There were also no differences in hospitalizations, admissions or use of steroids for asthma exacerbations between groups.

\section{Discussion}

In our multiethnic Asian population with severe asthma, we detected a significant association between Aspergillus sensitization and uncontrolled asthma. Patients with Aspergillus sensitization had more exacerbations requiring steroid bursts, as well as evidence of airflow obstruction. No similar associations were found with sensitization to any other allergens. A high prevalence of allergen sensitization was present in our cohort, with sensitization to HDM being commonest, and most patients were sensitized to more than a single allergen.

Singapore is the world's only island city-state. It lies $1^{\circ}$ north of the equator, has a tropical climate and stays hot and 
humid throughout the year. The population of $\sim 5,600,000$ consists of $74.1 \%$ Chinese, $13.4 \%$ Malay, 9.2\% Indian and $3.3 \%$ other races. ${ }^{10}$ Majority of asthmatics are managed by primary health care services, but more complex asthmatics have fast access to specialists in the hospitals. The Singapore General Hospital Difficult-to-treat/Severe Asthma Clinic is one such clinic and sees more than 600 patient attendances a year with majority of referrals from primary health care services or other specialists. However, despite its first world economy status and having one of the best health care systems in the world, ${ }^{11}$ Singapore is an intermediate-risk country for asthma prevalence, but a high-risk country for asthma death. ${ }^{12}$ The reason for this is likely to be multifactorial, including problems of adherence, health literacy and possibly, environmental factors such as allergen exposure and air pollution.

The prevalence of allergen sensitization and outcomes in a severe asthma population in Singapore (as for the rest of Asia) is not well described. Despite this, a study from North India reported high occurrences (50.9\%) of Aspergillus sensitization in patients with severe asthma; however, this work only included patients admitted to the intensive care unit for asthma, which is not necessarily representative of the severe asthma population managed in secondary health care. ${ }^{13} \mathrm{~A}$ separate study performed by the same group reported an association between Aspergillus sensitization and poorer lung function in asthma patients. ${ }^{14}$ Again, this study was not designed to evaluate a severe asthma population, which has been characterized in our work. In our severe asthma cohort consisting of various ethnic groups (Chinese, Malay and Indian), more than one in ten were sensitized to Aspergillus. Our study is one of the few that describe the prevalence of Aspergillus sensitization in patients with severe asthma in Asia. Our reported prevalence is lower than a pooled prevalence of $28 \%$ (95\% CI: $24 \%-34 \%$ ) from a meta-analysis of 20 observational studies, none of which was performed in an Asian context. ${ }^{15}$ However, these included studies were not restricted to the severe asthma population, a population among asthmatics that carries the greatest morbidity and use of health care resources. A UK-based study reported higher fungal sensitization prevalence rates of $66 \%$ among asthmatics requiring GINA step 4 or 5 medication. ${ }^{16}$ Such wide discrepancies in prevalence are likely explained by differing methodological approaches. We solely used SPT for Aspergillus mix in our study, while the UK group employed both SPT and/or specific serum IgE to a variety of fungi and/or yeasts including Aspergillus, Candida and Alternaria. Despite this, prevalence of sensitization to A. fumigatus alone was $45 \%$ in their population, therefore highlighting highlighting the possibility of reduced sensitivity when using SPT alone, but also the likely influence of genetics and environmental difference in allergen sensitization in an Asian setting. Even in our study, differences in Aspergillus sensitization were found among the different ethnic groups, although not reaching statistical significance.

We also report a significant degree of sensitization to general allergens in our cohort; $78.6 \%$ of patients had sensitization to one or more allergens. This is comparable to previous studies which have collated data on severe asthma. The SARP study ${ }^{17}$ and a multicenter UK ENFUMOSA ${ }^{18}$ study of severe asthma reported allergen sensitization rates of $71 \%$ and $68.6 \%$, respectively, with sensitization to HDM being the most common (71.0\%). A unique observation from our data set appears to be the high prevalence of BT sensitization. While this is interesting, it is not unexpected as BT is commonly described in the tropics at low elevations that are hot and wet, with high summer rainfall. ${ }^{19}$ It is also one of the predominant allergens in Singapore ${ }^{20}$ and is the predominant sensitized allergen previously described in Singaporean and Malaysian asthmatic patients. ${ }^{21,22}$ Despite its frequency, it did not independently and significantly contribute to uncontrolled severe asthma outcomes like that demonstrated for Aspergillus.

Our study adds to work reporting the key association between fungal sensitization, frequent exacerbations and life-threatening asthma in a population with severe asthma as defined by medication requirements (GINA step 4 or 5). ${ }^{23}$ While O'Driscoll et $\mathrm{al}^{6}$ and others ${ }^{24,25}$ had reported the association between fungal sensitization and multiple hospital admissions, patients in their study had differing asthma severities (British Thoracic Society guidelines steps $1-4),{ }^{26}$ making conclusions difficult to draw, particularly with regard to severe asthma.

Aspergillus sensitization was also associated with airflow obstruction. This is consistent with prior work reporting the association of $A$. fumigatus sensitization with reduced lung function and bronchiectasis in patients with asthma. ${ }^{7,8}$ Sensitization to $A$. fumigatus is associated with reduced lung function in several chronic respiratory diseases, including cystic fibrosis $(\mathrm{CF})^{27}$ and chronic obstructive pulmonary disease. ${ }^{28}$ The sensitization state is recognized for its clinical and prognostic importance with immunologic studies illustrating the combined use of serum IgE, Aspergillus-specific IgE and CD203c, a basophil surface marker in making the diagnosis of this clinical state in difficult cases. ${ }^{29-32}$ There is lack of data on specifically documenting the coexistence of bronchiectasis, fixed airflow obstruction and Aspergillus sensitization; however, work has been performed associating bronchiectasis with fungal sensitization. ${ }^{7,8}$

While it remains uncertain if the relationship between Aspergillus sensitization and reduced lung function is causal, 
the underlying pathogenesis of SAFS is believed to be in part related to triggering of the immune response from continued or repeated exposure to fungal spores. ${ }^{33}$ This is similar to ABPA, where a predominant T-helper type 2 inflammatory response occurs in response to Aspergillus' antigens in the airways. ${ }^{34,35}$ Recent data from Woolnough et al further corroborate the importance of Aspergillus sensitization in asthma, irrespective of its severity. ${ }^{34}$ They showed that IgE sensitization alone (without meeting the criteria for ABPA) to A. fumigatus is associated with fixed airflow obstruction and number of radiologic abnormalities; the latter finding was also illustrated in the context of $\mathrm{CF}^{36,37}$

There is a growing body of evidence to suggest a significant degree of airway colonization in patients sensitized to A. fumigatus; however, importantly, colonization by this thermotolerant fungus is unrelated to its allergic manifestations. ${ }^{38,39}$ Importantly, $\sim 60 \%$ of patients with moderate to severe asthma and IgE sensitization to A. fumigatus have positive sputum culture. ${ }^{7} A$. fumigatus polymerase chain reaction, a more sensitive method for its detection compared to culture alone, was positive in $70 \%$ of severe asthma with Aspergillus sensitization (SAAS) patients. ${ }^{40}$ Subgroup analysis revealed that $A$. fumigatus polymerase chain reaction became negative following treatment with itraconazole, ${ }^{40} \mathrm{a}$ finding which was also illustrated in $\mathrm{CF}^{39}$ Taken together, it is therefore plausible that antifungal therapy may be of benefit in patients with SAFS or SAAS; however, due to different methodologies in prior studies (including patient selection, duration of antifungal treatment and end points), strong conclusions cannot be drawn. ${ }^{41-44}$

There are currently no established treatment guidelines for SAFS. However, clinicians extrapolate data from studies in ABPA, which may not be necessarily representative of this unique clinical state. There is also emerging evidence that azoles may reduce bronchial hyperresponsiveness and improve symptoms, while reducing oral steroid requirements. However, these data were derived from patients sensitized to Trichophyton, a less-common fungus. ${ }^{42}$ Improvements in symptoms in patients with asthma and chronic rhinosinusitis with antifungal therapy have been recently described; however, their mechanisms remain unclear. ${ }^{43}$ A randomized placebo-controlled study (FAST) illustrated significant improvements in Asthma Quality of Life Questionnaires at 32 weeks with itraconazole use for SAFS. ${ }^{44}$ Conversely, the EVITA3 trial failed to show any effect on Asthma quality of life questionnaire (AQLQ) or asthma exacerbations at 52 weeks with voriconazole use in A. fumigatus-sensitized asthmatics. ${ }^{41}$ Of note, however, the duration of treatment in EVITA3 was shorter than that in the FAST trial (12 vs 32 weeks, respectively), and the itraconazole used in the latter likely had stronger effects on increasing corticosteroid availability. ${ }^{45}$

Our study also highlights the clinical importance of SAFS, a phenotype of severe asthma with evidence of fungal sensitization in the absence of ABPA. ${ }^{9}$ In addition, we propose that further characterization of this group into subgroups is now warranted, and here, we identify SAAS. This group of patients appears to have more frequent exacerbations and associated airflow obstruction; however, it may be underrecognized due to the absence of overt radiologic abnormalities such as bronchiectasis. SAAS patients may be potentially amenable to therapeutic interventions such as antifungal use to prevent exacerbations and achieve better disease control. Our study did not, however, include descriptions of radiologic abnormalities such as bronchiectasis and/or IgE levels, as these were not routinely performed in all patients. These would have been helpful to further characterize SAAS and ABPA in our cohort. Consequently, we were not able to reliably exclude ABPA in each case and definitively establish SAAS as a diagnosis of exclusion in this study, which is a limitation of our work. Additionally, we did not test for other fungal or yeast allergens such as Penicillium and Candida species that may have a role in cross-sensitization in our cohort.

While our findings have potential implications in identifying Aspergillus-sensitized severe asthma patients with poorer clinical outcomes, our study is limited by use of SPT alone as a marker of sensitization, without direct measures of allergen-specific IgE. We, therefore, have potentially underestimated the true prevalence of Aspergillus sensitization in our population. Opinion, however, is conflicting with regard to the utility of each of these measures to determine true sensitivity. SPT has been suggested to be more sensitive in detecting sensitization to aeroallergens in asthma, ${ }^{46}$ while other important studies have reported higher sensitivity by testing for $A$. fumigatus-specific IgE levels compared to Aspergillus SPT alone. ${ }^{47}$ A study comparing SPT and specific IgE measurements in severe asthma has suggested a degree of discordance, and both SPT and specific serum $\operatorname{IgE}$ are preferred for more accurate identification of fungal sensitization. ${ }^{16}$

\section{Conclusion}

The prevalence of allergen sensitization in our multiethnic Asian cohort with severe asthma is high at $78.2 \%$, and most patients were sensitized to more than a single allergen. Prevalence of Aspergillus-specific sensitization was $11.7 \%$. Sensitization to Aspergillus but no other allergens 
were independently associated with poorer lung function and frequent exacerbations in severe asthma requiring additional steroid bursts. Further characterization of the SAAS phenotype, a subgroup of SAFS that could potentially be amenable to therapeutic intervention with antifungal therapy, is now warranted to reduce exacerbations and achieve better asthma control.

\section{Acknowledgment}

The authors appreciate the help from Ms Karen Tan and Ms Florence Yeoh from the Department of Respiratory and Critical Care Medicine, Singapore General Hospital, for data collection.

\section{Disclosure}

The authors report no conflicts of interest in this work.

\section{References}

1. Moore WC, Meyers DA, Wenzel SE, et al. Identification of asthma phenotypes using cluster analysis in the severe asthma research program. Am J Respir Crit Care Med. 2010;181(4):315-323.

2. Amelink M, de Groot JC, de Nijs SB, et al. Severe adult-onset asthma: a distinct phenotype. J Allergy Clin Immunol. 2013;132(2):336-341.

3. Schatz M, Rosenwasser L. The allergic asthma phenotype. J Allergy Clin Immunol Pract. 2014;2(6):645-648.

4. Black PN, Udy AA, Brodie SM. Sensitivity to fungal allergens is a risk factor for life-threatening asthma. Allergy. 2000;55(5):501-504.

5. Zureik M, Neukirch C, Leynaert B, Liard R, Bousquet J, Neukirch F; European Community Respiratory Health Survey. Sensitisation to airborne moulds and severity of asthma: cross sectional study from European Community respiratory health survey. BMJ. 2002;325(7361): 411-414.

6. O'Driscoll BR, Hopkinson LC, Denning DW. Mold sensitization is common amongst patients with severe asthma requiring multiple hospital admissions. BMC Pulm Med. 2005;5:4.

7. Fairs A, Agbetile J, Hargadon B, et al. IgE sensitization to Aspergillus fumigatus is associated with reduced lung function in asthma. Am J Respir Crit Care Med. 2010;182(11):1362-1368.

8. Menzies D, Holmes L, McCumesky G, Prys-Picard C, Niven R. Aspergillus sensitization is associated with airflow limitation and bronchiectasis in severe asthma. Allergy Eur J Allergy Clin Immunol. 2011; 66(5):679-685.

9. Denning DW, O’Driscoll BR, Hogaboam CM, Bowyer P, Niven RM. The link between fungi and severe asthma: a summary of the evidence. Eur Respir J. 2006;27(3):615-626.

10. National Health Survey 2010 Singapore. Available from: https://www. moh.gov.sg/content/moh_web/home/Publications/Reports/2011/ national_health_survey2010.html. Accessed November 16, 2016.

11. The World Health Report 2000. Health systems: improving performance. Available from: www.who.int/whr/2000/en/.

12. Masoli M, Fabian D, Holt S, Beasley R; Global Initiative for Asthma (GINA) Program. The global burden of asthma: executive summary of the GINA Dissemination Committee report. Allergy. 2004; 59(5):469-478.

13. Agarwal R, Nath A, Aggarwal AN, Gupta D, Chakrabarti A. Aspergillus hypersensitivity and allergic bronchopulmonary aspergillosis in patients with acute severe asthma in a respiratory intensive care unit in North India. Mycoses. 2010;53(2):138-143.

14. Agarwal R, Noel V, Aggarwal AN, Gupta D, Chakrabarti A. Clinical significance of Aspergillus sensitisation in bronchial asthma. Mycoses. 2011;54(5):531-539.
15. Agarwal R, Aggarwal AN, Gupta D, Jindal SK. Aspergillus hypersensitivity and allergic bronchopulmonary aspergillosis in patients with bronchial asthma: systematic review and meta-analysis. Int $J$ Tuberc Lung Dis. 2009;13(8):936-944.

16. O'Driscoll BR, Powell G, Chew F, et al. Comparison of skin prick tests with specific serum immunoglobulin e in the diagnosis of fungal sensitization in patients with severe asthma. Clin Exp Allergy. 2009;39(11): 1677-1683.

17. Moore WC, Bleecker ER, Curran-Everett D, et al; National Heart, Lung, Blood Institute's Severe Asthma Research Program. Characterization of the severe asthma phenotype by the National Heart, Lung, and Blood Institute's Severe Asthma Research Program. J Allergy Clin Immunol. 2007;119(2):405-413.

18. The ENFUMOSA Study Group. The ENFUMOSA cross-sectional European multicentre study of the clinical phenotype of chronic severe asthma. Eur Respir J. 2003;22(3):470-477.

19. Calderón MA, Linneberg A, Kleine-Tebbe J, et al. Respiratory allergy caused by house dust mites: what do we really know? J Allergy Clin Immunol. 2015;136(1):38-48.

20. Chew FT, Zhang L, Ho TM, Lee BW. House dust mite fauna of tropical Singapore. Clin Exp Allergy. 1999;29(2):201-206.

21. Chew FT, Lim SH, Goh DY, Lee BW. Sensitization to local dust-mite fauna in Singapore. Allergy. 1999;54(11):1150-1159.

22. Yeoh SM, Kuo IC, Wang DY, et al. Sensitization profiles of Malaysian and Singaporean subjects to allergens from Dermatophagoides pteronyssinus and Blomia tropicalis. Int Arch Allergy Immunol. 2003;132(3): 215-220.

23. Medrek SK, Kao CC, Yang DH, Hanania NA, Parulekar AD. Fungal Sensitization is associated with increased risk of life-threatening asthma. J Allergy Clin Immunol Pract. 2016; pii: S2213-2198(16):30573-30576.

24. Global Initiative for Asthma (GINA); 2014. Available from: http:// ginaasthma.org/archived-reports/. Accessed November 16, 2016.

25. Chung KF, Wenzel SE, Brozek JL, et al. International ERS/ATS guidelines on definition, evaluation and treatment of severe asthma. Eur Respir J. 2014;43(2):343-373.

26. British thoracic society, Scottish Intercoll Guidel Networl. British guideline on the management of asthma. Thorax. 2014;69:1-192.

27. Moss RB. Allergic bronchopulmonary aspergillosis and Aspergillus infection in cystic fibrosis. Curr Opin Pulm Med. 2010;16(6):598-603.

28. Bafadhel M, McKenna S, Agbetile J, et al. Aspergillus fumigatus during stable state and exacerbations of COPD. Eur Respir J. 2014;43(1): 64-71.

29. Yii AC, Koh MS, Lapperre TS, Tan GL, Chotirmall SH. The emergence of Aspergillus species in chronic respiratory disease. Front Biosci (Schol Ed). 2017;9:127-138.

30. Mirković B, Lavelle GM, Azim AA, et al. The basophil surface marker CD203c identifies Aspergillus species sensitization in patients with cystic fibrosis. J Allergy Clin Immunol. 2016;137(2):436-443.

31. Hector A, Chotirmall SH, Lavelle GM, et al. Chitinase activation in patients with fungus-associated cystic fibrosis lung disease. J Allergy Clin Immunol. 2016;138(4):1183-1189.

32. Gernez Y, Waters J, Mirković B, et al. Blood basophil activation is a reliable biomarker of allergic bronchopulmonary aspergillosis in cystic fibrosis. Eur Respir J. 2016;47(1):177-185.

33. Agarwal R. Severe asthma with fungal sensitization. Curr Allergy Asthma Rep. 2011;11(5):403-413.

34. Kauffman HF. Immunopathogenesis of allergic bronchopulmonary aspergillosis and airway remodeling. Front Biosci. 2003;8:e190-e196.

35. Chotirmall SH, Al-Alawi M, Mirkovic B, et al. Aspergillus-associated airway disease, inflammation, and the innate immune response. Biomed Res Int. 2013;2013:723129.

36. Woolnough KF, Richardson M, Newby C, et al. The relationship between biomarkers of fungal allergy and lung damage in asthma. Clin Exp Allergy. 2017;47(1):48-56.

37. McMahon MA, Chotirmall SH, McCullagh B, Branagan P, McElvaney NG, Logan PM. Radiological abnormalities associated with Aspergillus colonization in a cystic fibrosis population. Eur J Radiol. 2012;81(3):e197-e202. 
38. Chotirmall SH, Branagan P, Gunaratnam C, McElvaney NG. Aspergillus/allergic bronchopulmonary aspergillosis in an Irish cystic fibrosis population: a diagnostically challenging entity. Respir Care. 2008;53(8):1035-1041.

39. Coughlan CA, Chotirmall SH, Renwick J, et al. The effect of Aspergillus fumigatus infection on vitamin D receptor expression in cystic fibrosis. Am J Respir Crit Care Med. 2012;186(10):999-1007.

40. Farrant J, Brice H, Fowler S, Niven R. Fungal sensitisation in severe asthma is associated with the identification of Aspergillus fumigatus in sputum. J Asthma. 2016;53(7):732-735.

41. Agbetile J, Bourne M, Fairs A, et al. Effectiveness of voriconazole in the treatment of Aspergillus fumigatus-associated asthma (EVITA3 study). J Allergy Clin Immunol. 2014;134(1):33-39.

42. Ward GW, Woodfolk JA, Hayden ML, Jackson S, Platts-Mills TA. Treatment of late-onset asthma with fluconazole. J Allergy Clin Immunol. 1999;104(3 Pt 1):541-546.
43. Li E, Maskatia R, Porter P, Corry DB. A retrospective study of the effect of antifungal therapy on a cohort with asthma and chronic rhinosinusitis. J Allergy Clin Immunol. 2016;137(2):AB214.

44. Denning DW, O'Driscoll BR, Powell G, et al. Randomized controlled trial of oral antifungal treatment for severe asthma with fungal sensitization: the fungal asthma sensitization trial (FAST) study. Am J Respir Crit Care Med. 2009;179(1):11-18.

45. Raaska K, Niemi M, Neuvonen M, Neuvonen PJ, Kivistö KT. Plasma concentrations of inhaled budesonide and its effects on plasma cortisol are increased by the cytochrome P4503A4 inhibitor itraconazole. Clin Pharmacol Ther. 2002;72(4):362-369.

46. Bousquet PJ, Chatzi L, Jarvis D, Burney P. Assessing skin prick tests reliability in ECRHS-I. Allergy. 2008;63(3):341-346.

47. Agarwal R, Maskey D, Aggarwal AN, et al. Diagnostic performance of various tests and criteria employed in allergic bronchopulmonary aspergillosis: a latent class analysis. PLoS One. 2013;8(4):e61105.
Journal of Asthma and Allergy

\section{Publish your work in this journal}

The Journal of Asthma and Allergy is an international, peer-reviewed open access journal publishing original research, reports, editorials and commentaries on the following topics: Asthma; Pulmonary physiology; Asthma related clinical health; Clinical immunology and the immunological basis of disease; Pharmacological interventions and

\section{Dovepress}

new therapies. This journal is included in PubMed. The manuscript management system is completely online and includes a very quick and fair peer-review system, which is all easy to use. Visit http://www. dovepress.com/testimonials.php to read real quotes from published authors. 